Rabaska

Revue d'ethnologie de l'Amérique française

\title{
Edmond-Joseph Massicotte, illustrateur (1875-1929). Une exposition, un livre, deux points de vue
}

Volume 4, 2006

URI : https://id.erudit.org/iderudit/039448ar

DOI : https://doi.org/10.7202/039448ar

Aller au sommaire du numéro

Éditeur(s)

Société québécoise d'ethnologie

ISSN

1703-7433 (imprimé)

1916-7350 (numérique)

Découvrir la revue

Citer ce document

(2006). Edmond-Joseph Massicotte, illustrateur (1875-1929). Une exposition, un livre, deux points de vue. Rabaska, 4, 123-123. https://doi.org/10.7202/039448ar d'utilisation que vous pouvez consulter en ligne.

https://apropos.erudit.org/fr/usagers/politique-dutilisation/ 
Points de vue / exposition

\section{Edmond-Joseph Massicotte, illustrateur (1875-1929) Une exposition, un livre, deux points de vue}

L'exposition Edmond-Joseph Massicotte, illustrateur, qui a récemment été présentée au Musée national des beaux-arts du Québec, a profondément ému le comédien Yves Massicotte, qui a bien voulu faire part aux lecteurs de RABASKA de son témoignage sur son illustre parent, et qui, en professionnel accompli, sait regarder une œuvre, la situer dans son contexte et l'apprécier pour ce qu'elle est plutôt que ce que le goût du jour veut y voir. Nous avons aussi demandé à Bernard Genest, ethnologue réputé qui a spécialement étudié les dessins de l'artiste, dont il a notamment publié les résultats dans son livre Massicotte et son temps, de nous livrer son point de vue d'expert sur cette exposition et sur le livre qui l'accompagne.

\section{Hommage d'un comédien à son grand-oncle, le peintre-illustrateur québécois Edmond-J. Massicotte (1875-1929)}

Yves MASSICOTTE

Montréal

L'exposition des œuvres majeures d'Edmond-J. Massicotte au Musée national des beaux-arts du Québec, en 2005 et 2006, fut à mes yeux une résurgence artistique d'une très grande importance. Mes visites à cette exposition m'ont profondément secoué, et aujourd'hui, au moment d'écrire cet hommage, mon émotion ne s'est pas encore résorbée ; au contraire, elle suscite en moi des débats d'idées et un brassage de mes valeurs artistiques que je tente quotidiennement de démêler et d'ordonner.

L'hommage que je veux rendre à ce grand-oncle, que je n'ai malheureusement pas connu de son vivant, débutera - et j'y tiens - par un coup de chapeau à son petit-fils Jean-François Pothier, ébéniste, qui par sa ténacité, 